\title{
CORRECTION
}

View Article Online

View Journal I View Issue

\section{Correction: Silver nanoparticles: green synthesis, self-assembled nanostructures and their application as SERS substrates}

Cite this: New J. Chem., 2015 39,3150

DOI: $10.1039 / c 5 n j 90009 c$

www.rsc.org/njc
Elias de Barros Santos, ${ }^{*}$ Natiara Vaughn Madalossi, Fernando Aparecido Sigoli and Italo Odone Mazali*

Correction for 'Silver nanoparticles: green synthesis, self-assembled nanostructures and their application as SERS substrates' by Elias de Barros Santos et al., New J. Chem., 2015, DOI: 10.1039/c4nj02239d.

" $\mathrm{NH}_{3}$ " should be changed to " $\mathrm{NH}_{2}$ " in Fig. 5 . The correct Fig. 5 is shown below.

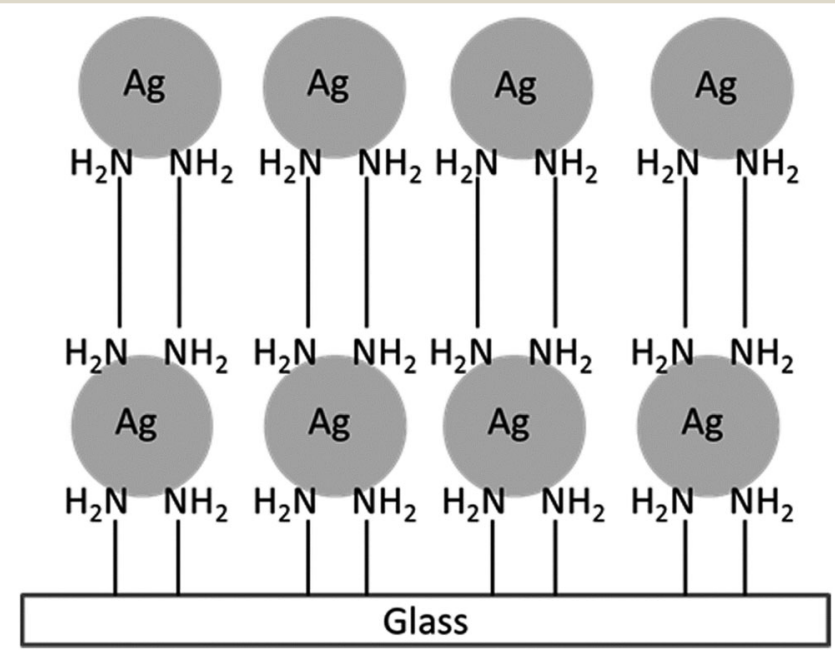

Fig. 5 Representation of the bilayer AgNP structure on a $\mathrm{NH}_{2}$-modified glass slide. The APTMS sol gel molecules are the linker between the AgNP layers. Drawing not to scale, only for illustration.

The Royal Society of Chemistry apologises for these errors and any consequent inconvenience to authors and readers. 